\title{
Investigating the response of LAI to droughts in southern African vegetation using observations and model-simulations.
}

\author{
Shakirudeen Lawal ${ }^{1}$ Stephen Sitch ${ }^{2}$ Danica Lombardozzi ${ }^{3}$ Julia E.M.S. Nabel ${ }^{4}$ \\ Hao-Wei Wey ${ }^{4}$ Pierre Friedlingstein ${ }^{5}$ Hanqin Tian ${ }^{6}$ Bruce Hewitson ${ }^{1}$ \\ ${ }^{1}$ Climate System Analysis Group, Department of Environmental and Geographical \\ Science, University of Cape Town, Cape Town, 7700, South Africa \\ ${ }^{2}$ College of Life and Environmental Sciences, University of Exeter, Exeter EX4 4QE, \\ UK
}

${ }^{3}$ National Center for Atmospheric Research, Climate and Global Dynamics, Terrestrial Sciences Section, Boulder, CO 80305, USA

${ }^{4}$ Max Planck Institute for Meteorology, Hamburg, Germany

${ }^{5}$ College of Engineering, Mathematics and Physical Sciences, University of Exeter, Exeter EX4 4QF, UK

${ }^{6}$ School of Forestry and Wildlife Sciences, Auburn University, 602 Ducan Drive, Auburn, AL 36849, USA

*Corresponding author: lasd dr@yahoo.com

This PDF file includes: Figures S1 to S7 


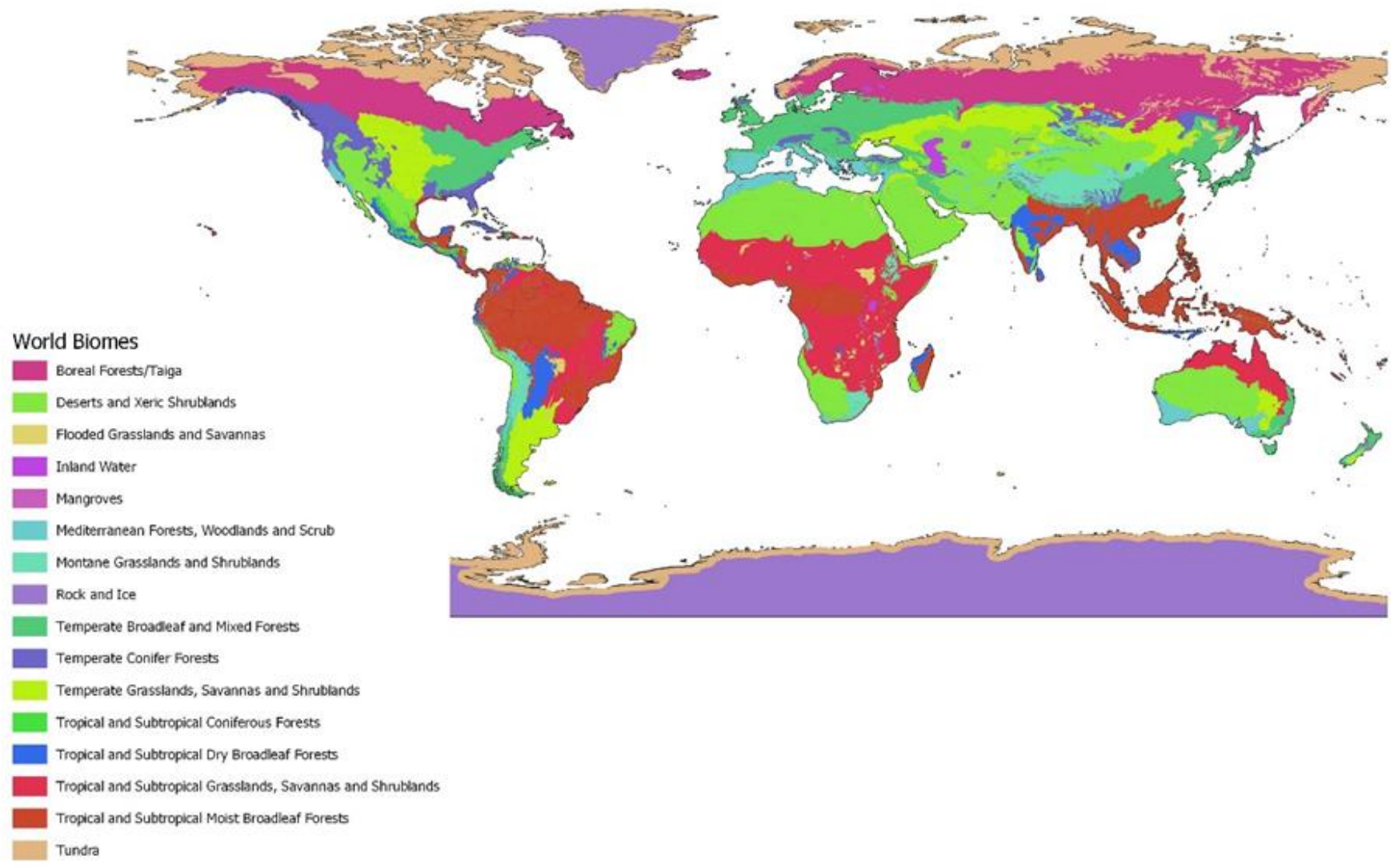



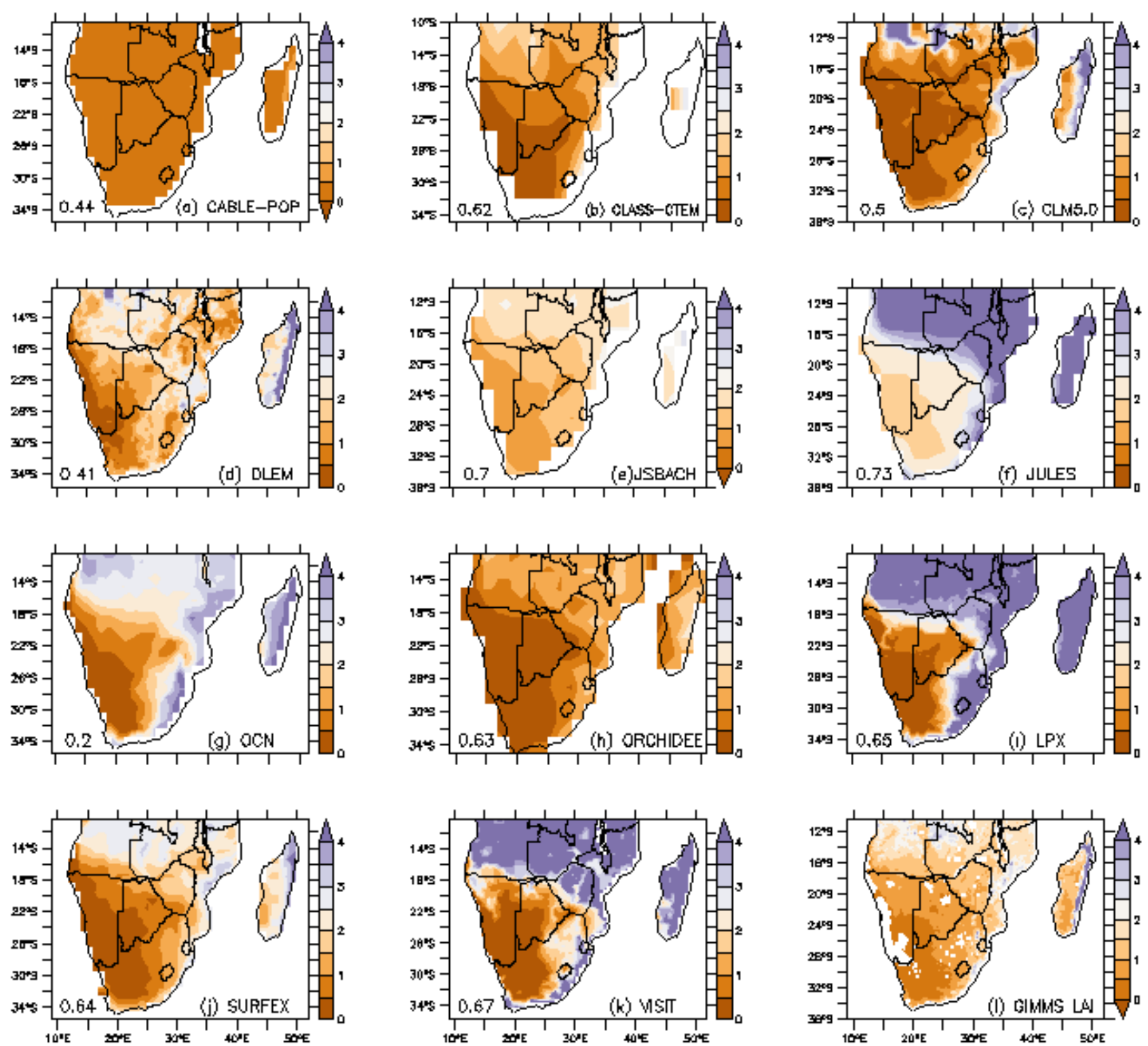

Figure S2. Spatial distribution of observed and simulated LAI over southern Africa; for the period 1982 - 2011. The spatial correlation values between models and GIMMS are indicated inside the panels. 

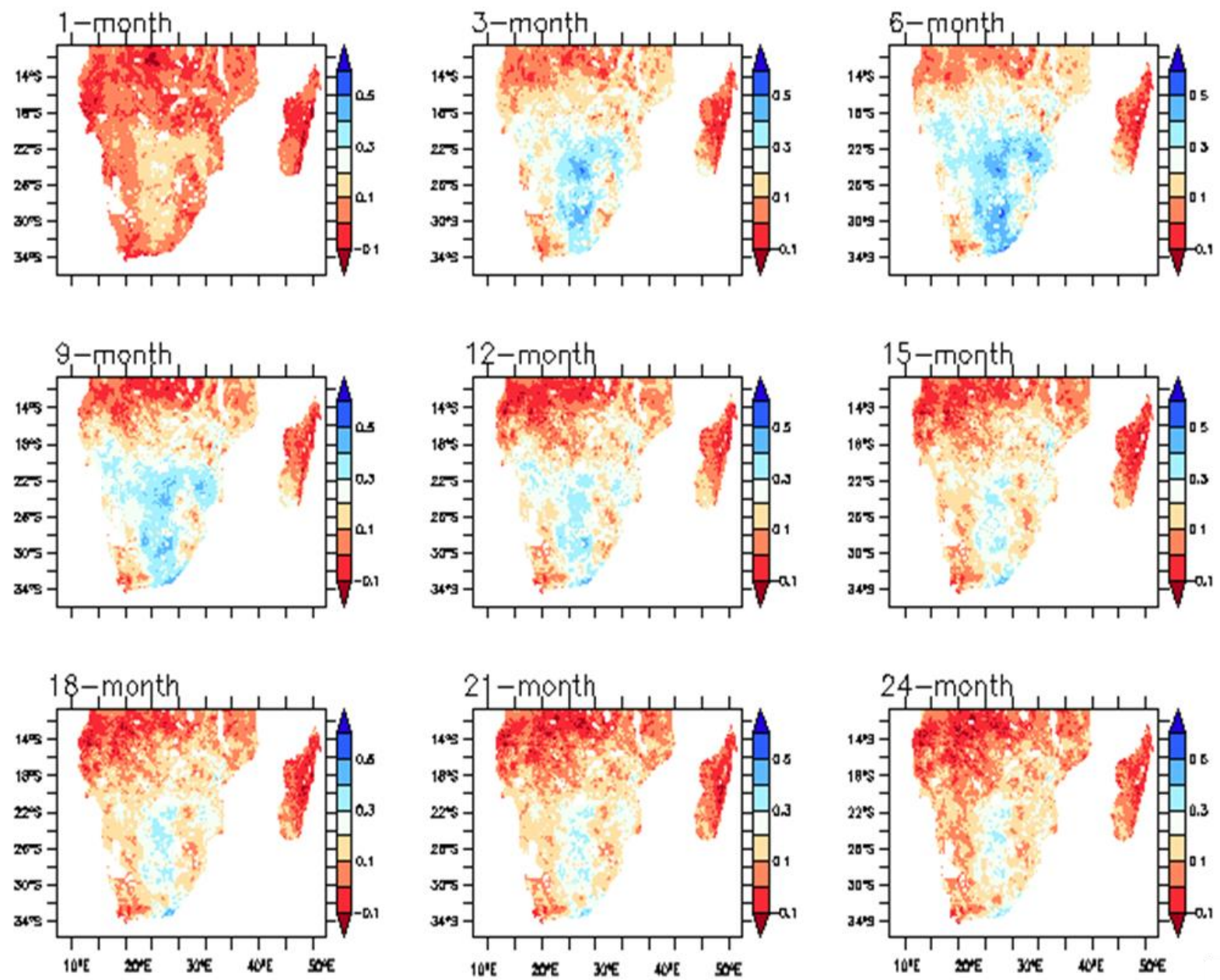

Figure S3. Spatial distribution of observed correlations at 1- to 24-month timescales over southern Africa for the period 1982 - 2011. 

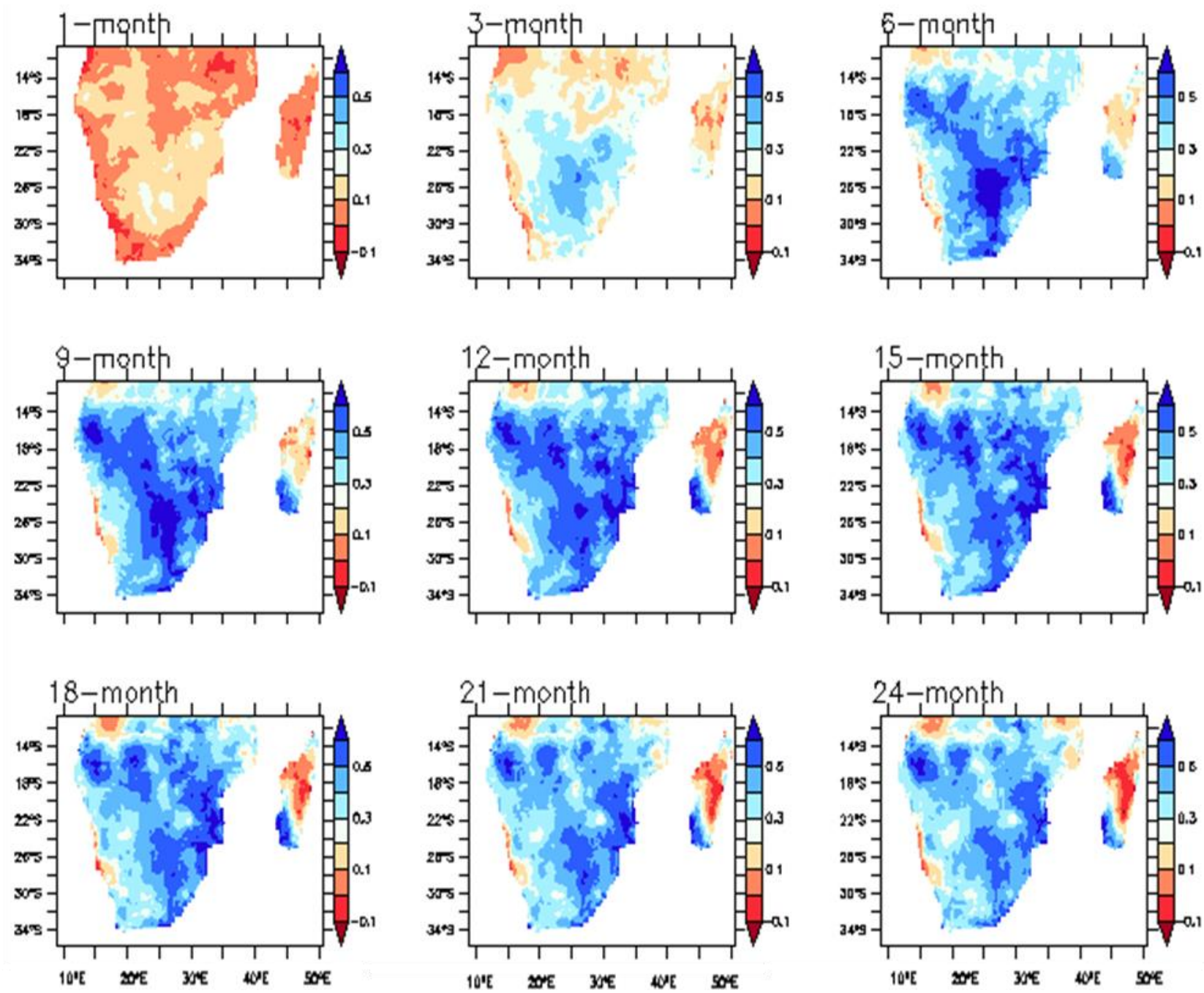

Figure S4. As in Fig. S3 but for the model ensemble median 

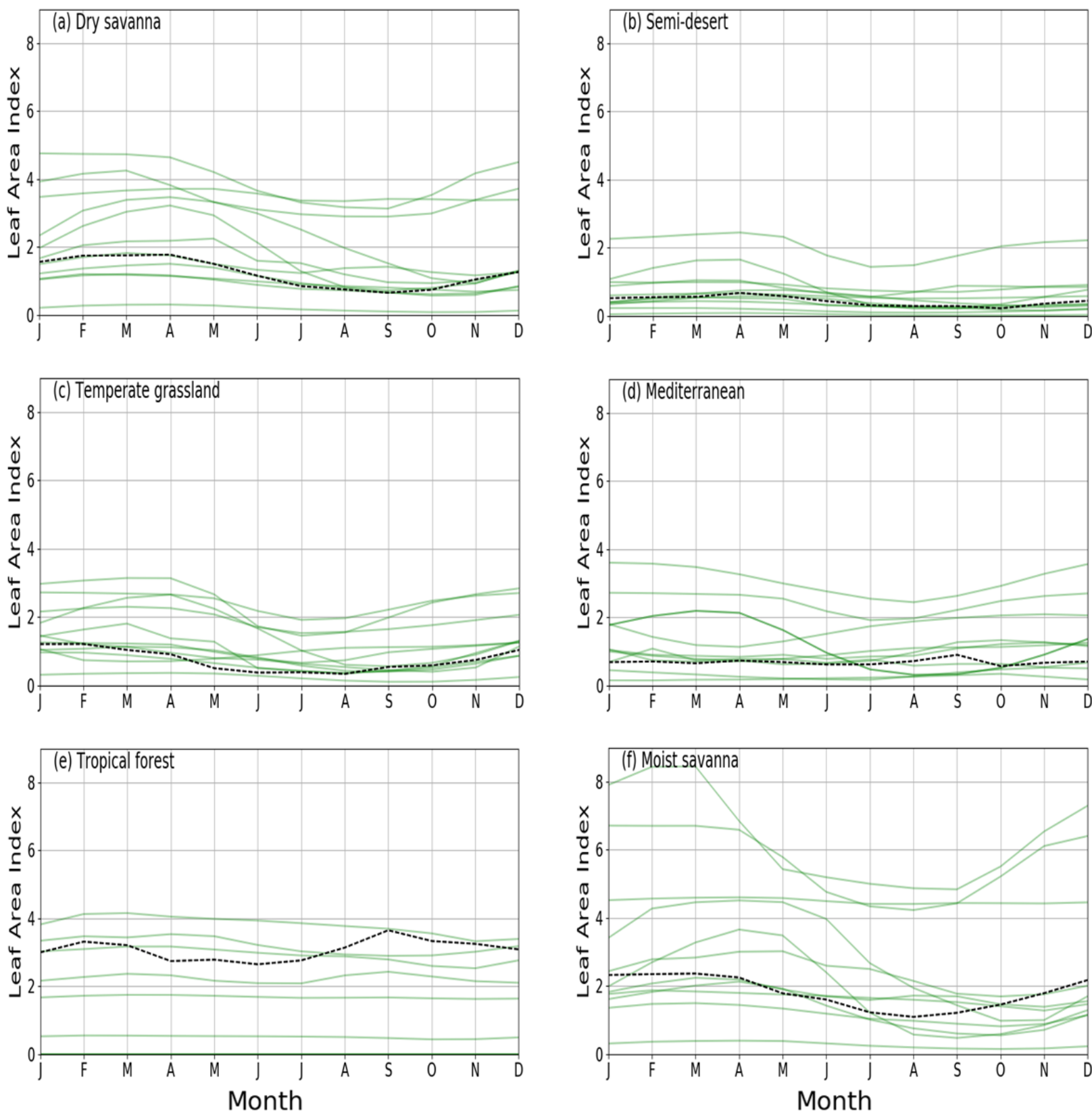

101 

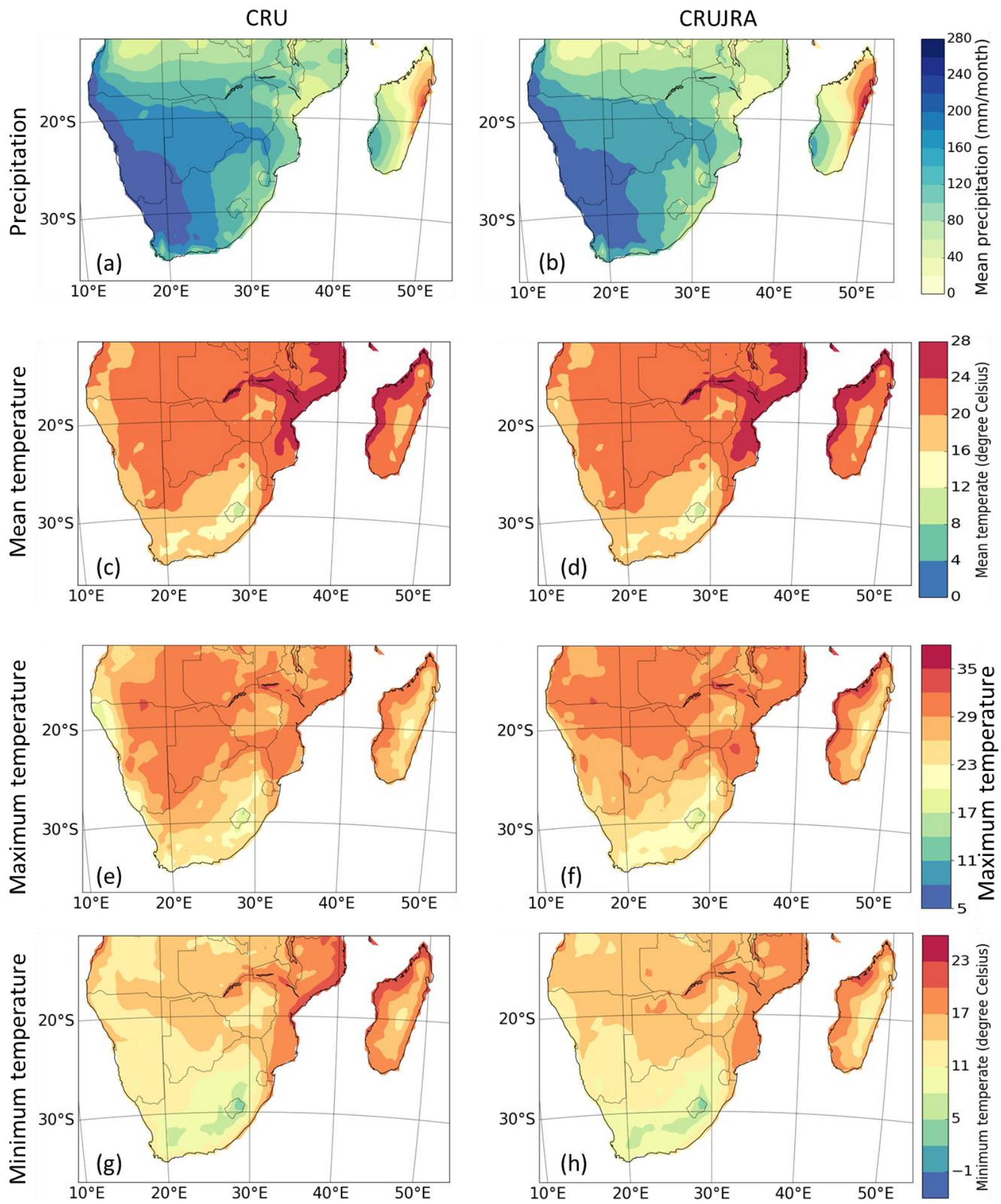

112 Figure S6. Spatial distribution of precipitation, mean temperature, maximum temperature and minimum temperature over southern Africa in CRU and CRUJRA; for the periods 1982 2011. 

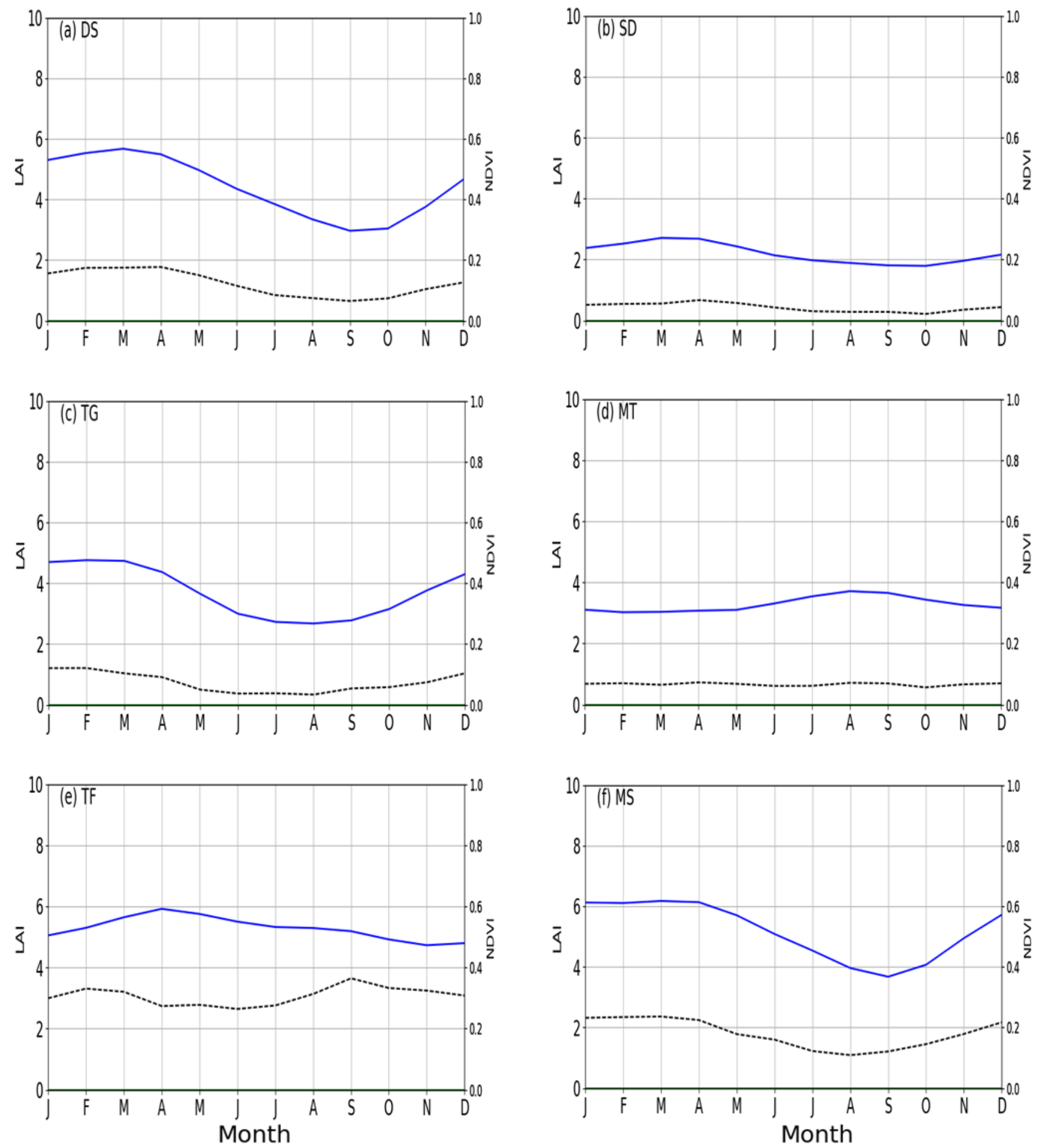

120 Figure S7. Annual cycle of observed LAI and NDVI across six biomes over southern Africa 121 for the period $1982-2011$. 